\title{
Sociodemographic and reproductive risk factors in cervical cancer
}

\author{
Tajinder Kaur*, Shaveta Garg, Sunita Mor
}

Department of Obstetrics and Gynaecology, MMIMSR Mullana, Ambala, Haryana, India

Received: 29 February 2016

Accepted: 29 March 2016

*Correspondence:

Dr. Tajinder Kaur,

E-mail: teji1305@gmail.com

Copyright: ( $\odot$ the author(s), publisher and licensee Medip Academy. This is an open-access article distributed under the terms of the Creative Commons Attribution Non-Commercial License, which permits unrestricted non-commercial use, distribution, and reproduction in any medium, provided the original work is properly cited.

\section{ABSTRACT}

Background: Cervical cancer is the leading cause of cancer deaths in women. In India, cervical cancer is the most common cancer in women followed by breast cancer. A numbers of risk factors reproductive as well as sociodemographic have been widely studied for cervical cancer. The countries where universal screening is restricted because of various reasons economical, lack of resources etcetera, a modified screening procedure which is targeted on the high risk population can help solve the problem.

Methods: This prospective study was conducted in a tertiary institute on sexually active women attending the gynaec OPD. A total of 200 women eligible for the study underwent a cytological evaluation and those with positive findings on Pap smear were followed by colposcopy directed biopsy. A detailed proforma including risk factors was filled for each patient and at the end of study data collected was tabulated in a master chart and was analyzed statistically.

Results: A total of 200 women underwent screening with Pap smear in present study. The Pap smear was normal in $93(46.5 \%)$ of cases, 77 (38.5\%) showed inflammatory smear and $3(1.5 \%)$ subjects had an unsatisfactory smear. The Pap smear was abnormal in 27 (23.5\%) of cases constituting 17 (8.5\%) cases of LSIL, 2 (1\%) of HSIL and 8 (4\%) cases of AGS. All the women with LSIL and HSIL were subjected to colposcopy directed biopsy. Amongst 17 cases of LSIL on pap 8 came out as LSIL, 2 were HSIL and rest 7 were inflammatory after histopathological analysis. The 2 cases of HSIL on pap were confirmed as carcinoma in situ after biopsy. The maximum incidence of SIL of $16.66 \%$ was observed in age group of more than 40 years. The majority of cases of SIL, $12(63.2 \%)$ had coitus before the age of 18 years. A positive correlation of SIL was seen with decreasing socioeconomic status, 8 (42.1\%) of cases of SIL belonged to the low socioeconomic status while this group constituted only $23 \%$ of the total subjects.

Conclusions: The frequency of malignant and premalignant lesions was found to be significant, further emphasizing the importance of screening of cervical cancer. The prevalence of carcinoma cervix increases with age, in those with young age at first coitus, lower socioeconomic status and with low education level. A modified screening method can be an effective strategy to control cervical cancer in a developing country like India, where cost and manpower is an issue.

Keywords: Cervical cancer, Pap smear, HSIL, LSIL, AGS

\section{INTRODUCTION}

Cervical cancer is the leading cause of cancer deaths in women. Worldwide 231,000 women die due to cervical cancer, with over $80 \%$ of these deaths occurring in developing countries. In India, cervical cancer is the most common cancer in women followed by breast cancer, accounting for $26.1-43.8 \%$ of all cancers in Indian women. ${ }^{1}$ India's cervical cancer age standardized incidence rate $(30.7$ per 100,000$)$ and age standardized mortality rate $(17.4$ per 100,000$)$ are the highest in South East Asia. $^{2}$

According to The American cancer society the risk factors for cervical cancer are smoking, hormonal contraception, multiple pregnancies, early age at first 
intercourse and first pregnancy. It is magnified by early use of oral contraceptives. ${ }^{3}$ It has been shown that women who initiate sexual activity before the age of 16 have a twofold or greater risk compared with women becoming sexually active after 20 years. Also young age at marriage signifies a longer duration of active sexual life.

Cervical cancer is more prevalent in women living in poor conditions with a low income and indifferent education. ${ }^{4}$

\section{METHODS}

This study was conducted on sexually active women attending the Gynae OPD at MMIMSR, Mullana, Ambala, Haryana, India

The inclusion criteria were sexually active women with age between $18-50$ years.

The exclusion criteria were pregnant female, women who had hysterectomy or treated for cervical pre cancer or cancer in the past.

A total of 200 women eligible for study underwent a cytological evaluation of cervical smears and those with positive findings on Pap smear were followed by colposcopy directed cervical biopsy.

A structured questionnaire was designed to assess the risk factors associated with the development of cervical cancer including sociodemographic factors, reproductive variables and presenting complaints.

In all women a scrape smear was taken from the squamocolumnar junction of cervix and fixed in $95 \%$ ethyl alcohol. The smears were stained using papanicolau method and read by the pathologist. All smears were interpreted according to the bethesda system. ${ }^{5}$

Those with positive test result on Pap smear were further subjected to colposcopy directed biopsy. A proforma was filled for each patient and at the end of study data collected was tabulated in a master chart and was analyzed statistically.

\section{RESULTS}

A total of 200 women underwent screening with Pap smear in the present study. The Pap smear was normal in $93(46.5 \%)$ cases, $77(38.5 \%)$ showed inflammatory smear and $3(1.5 \%)$ subjects had unsatisfactory smear. The Pap smear was abnormal in 27 (23.5\%) cases constituting $17(8.5 \%)$ cases of LSIL, 2 (1\%) of HSIL and $8(4 \%)$ cases of AGS (Table 1). All the women with LSIL and HSIL were subjected to colposcopy directed biopsy. Amongst 17 cases of LSIL on Pap, 8 came out as LSIL, 2 were HSIL and rest 7 were inflammatory after histopathological analysis. The 2 cases of HSIL on Pap were confirmed as carcinoma in situ after biopsy (Table 2).
Table 1: Results of Pap smear.

\begin{tabular}{|lll|}
\hline Pap smear report & Number & Percentage \\
\hline Normal & 93 & 46.5 \\
\hline Inflammatory smear & 77 & 38.5 \\
\hline Unsatisfactory & 3 & 1.5 \\
\hline LSIL & 17 & 8.5 \\
\hline HSIL & 2 & 1.0 \\
\hline AGS & 8 & 4.0 \\
\hline Total & $\mathbf{2 0 0}$ & $\mathbf{1 0 0 . 0}$ \\
\hline
\end{tabular}

Table 2: Pap test and biopsy.

\begin{tabular}{|lllll|}
\hline $\begin{array}{c}\text { Pap } \\
\text { Smear }\end{array}$ & $\begin{array}{l}\text { Benign } \\
\text { lesions }\end{array}$ & $\begin{array}{l}\text { Mild } \\
\text { dysplasia } \\
\text { (LSIL) }\end{array}$ & $\begin{array}{l}\text { Moderate } \\
\text { dysplasia } \\
\text { (HSIL) }\end{array}$ & CIS \\
\hline LSIL & 7 & 8 & 2 & 0 \\
\hline HSIL & 0 & 0 & 0 & 2 \\
\hline AGUS & 4 & 4 & 0 & 0 \\
\hline
\end{tabular}

Table 3: SIL frequency in association with risk factors.

\begin{tabular}{|c|c|c|c|}
\hline & of cases & $\begin{array}{l}\text { Sil frequency in } \\
\text { group }\end{array}$ & $\begin{array}{l}\text { Total } \\
\% \text { sil }\end{array}$ \\
\hline \multicolumn{4}{|l|}{ Age } \\
\hline 20-30 years & 59 & $6(10.17 \%)$ & $31.6 \%$ \\
\hline $31-40$ years & 117 & $9(7.69 \%)$ & $47.4 \%$ \\
\hline $41-50$ years & 24 & $4(16.66 \%)$ & $21 \%$ \\
\hline \multicolumn{4}{|c|}{ Age at first coitus } \\
\hline $15-18$ years & 121 & $12(9.9 \%)$ & $63.2 \%$ \\
\hline 19-22 years & 70 & $5(7.1 \%)$ & $26.3 \%$ \\
\hline$>22$ years & 9 & $2(22.2 \%)$ & $10.5 \%$ \\
\hline \multicolumn{4}{|c|}{ Socioeconomic status } \\
\hline Upper & 45 & $4(8.8 \%)$ & $21.19 \%$ \\
\hline Middle & 109 & $7(6.4 \%)$ & $36.8 \%$ \\
\hline Lower & 46 & $8(17.4 \%)$ & $42.1 \%$ \\
\hline \multicolumn{4}{|l|}{ Education status } \\
\hline Literate & 96 & $7(7.29 \%)$ & $36.8 \%$ \\
\hline Illiterate & 104 & $12(11.53 \%)$ & $63.2 \%$ \\
\hline \multicolumn{4}{|c|}{ Cervical condition } \\
\hline Healthy cervix & 49 & $2(4.08 \%)$ & $10.5 \%$ \\
\hline Cervical Erosion & 151 & $17(11.25 \%)$ & $89.5 \%$ \\
\hline \multicolumn{4}{|c|}{ Post coital bleed } \\
\hline Present & 28 & $5(17.85 \%)$ & $26.3 \%$ \\
\hline Absent & 172 & $14(8.14 \%)$ & $73.7 \%$ \\
\hline
\end{tabular}

The incidence of LSIL was studied in relation with various factors like age, parity, age at first coitus, socioeconomic status, education status and cervical condition in examination. The maximum incidence of SIL of $16.66 \%$ was observed in age group of more than 40 years. The majority of cases of SIL, 12 (63.2\%) had coitus before the age of 18 years. A positive correlation of SIL was seen with decreasing socioeconomic status, 8 $(42.1 \%)$ of cases of SIL belonged to the low socioeconomic status while this group constituted only $23 \%$ of the total subjects. Although the relative 
percentage of illiterate and literate cases was 52 and $48 \%$ respectively, the frequency of SIL was found to be higher that is $63.2 \%$ in the illiterate group. In addition a significant association was observed with the symptoms of post coital bleed, $17.85 \%$ of 28 cases with postcoital bleed had SIL. A marked difference was observed as regard to SIL in healthy and unhealthy cervix. Unhealthy cervix was present in 17 out of 19 cases of SIL and only 2 cases of SIL belonged to the group with healthy cervix. Increasing parity has been established as a high risk factor for carcinoma cervix but in our study all cases of SIL were found in parity $<4$ as group with parity $>4$ constituted a small number of 18 cases only (Table 3 ).

\section{DISCUSSION}

A wide variation in the incidence of abnormal Pap smear has been reported in the literature ranging from $5.2 \%$, $4.6 \%$ to $15 \%$ as reported by Manos et al, Engineer AD et al and Sherwani RK et al respectively. ${ }^{6,7}$ We observed an incidence of $13.5 \%$ of abnormal smears in our study, the higher incidence can be attributed to the fact that ours was an opportunistic screening.

Out of the abnormal smear (27), mild dysplasia was seen in $17(62.96 \%)$ subjects which is comparable to those reported by Luthra et al $(62.6 \%)$ and HSIL was observed in $1 \%$ of cases in our study, Gehlot et al and Fonn S et al report HSIL incidence of $1 \%$ and $1.8 \%$ respectively. ${ }^{9,10,11}$

A number of studies support a higher incidence of cervical cancer with increasing age. A higher frequency of SIL $(12.4 \%)$ was found in the present study in women over 40 years of age. Thulaseedharan JV et al observed 2.5 fold increased risk in women aged 50-59 years. Misra JS et al too observed higher frequency $(10.71 \%)$ of SIL in $>40$ years age group. ${ }^{12,13}$

Age at first coitus was studied as a risk factor. All the subjects were in a monogamous relationship and $88.5 \%$ had first coitus below the age of 22 years. It can be the reason for relatively higher incidence of SIL in our study. The frequency of SIL was higher $(9.9 \%)$ in group with first coitus below 18 years than the group with coitus between $19-22$ years of age $(7.1 \%)$. The group with first coitus at age $>22$ years constituted only 9 number of cases and cannot be taken as representative of this group. Herrero et al reported maximum risk of cervical cancer in women with first coitus between 14 and 15 years of age. ${ }^{14}$

Deficiency in the genital hygiene are associated with education level and low socioeconomic status, contributing to a no significant excess risk of cervical dysplasia. ${ }^{15}$ Jissa $\mathrm{V}$ et al observed that compared to those with no formal education, women with some formal education had a reduced risk of cervical cancer, as observed in the present study. ${ }^{12}$

The likelihood of having SIL and carcinoma cervix is significantly high in those whose cervix appears to be abnormal macroscopically. Misra JS observed an incidence of $14.1 \%$ versus $1.7 \%$ in unhealthy and healthy cervix respectively. ${ }^{13}$ Fonn $\mathrm{S}$ et al reported that healthy cervix are less likely to have abnormal outcome. ${ }^{11} \mathrm{~A}$ higher incidence of SIL (11.25\%) was observed in unhealthy cervix compared to healthy cervix $(4.08 \%)$ in the present study. The prevalence of post coital bleed in women with cervical cancer ranges from 0.7 to $39 \%$ and role of cytology for evaluation in post coital bleed is required. $^{16}$

The frequency of malignant and premalignant lesions was found to be significant, further emphasizing the importance of screening of cervical cancer. The prevalence of carcinoma cervix increases with age, in those with young age at first coitus, lower socioeconomic status and with low education level. A modified screening method can be an effective strategy to control cervical cancer in a developing country like India, where cost and manpower is an issue, as also suggested by Misra JS et al. ${ }^{13}$

\section{CONCLUSIONS}

A single lifetime screening based on high risk cases as defined in our study as well as a number of studies in the literature can prove to be a practical alternative. Health organizations can help in spreading awareness regarding modifiable risk factors as well as screening to reduce carcinoma cervix incidence.

Funding: No funding sources

Conflict of interest: None declared

Ethical approval: The study was approved by the Institutional Ethics Committee

\section{REFERENCES}

1. Parkin DM, Bray F, Ferley J. Estimating the world cancer burden: Globocan 2000. Int J Cancer. 2001;94:153-6.

2. Rasda D, Jyothi V, Maratha J. A strategic assessment of cervical cancer prevention and treatment services. Reproductive health. 2005;2:11.

3. Louie KS, Sanjose SD, Diaz M, Castellsague X, Herrero R, Meijer CJ, et al. Early age at first sexual intercourse and early pregnancy are risk factors for cervical cancer in developing countries. British Journal of Cancer. 2009;100(7):1191-97.

4. Genital Cancer. Tumours of the cervix uteri, Jeffcoats Principles of Gynecology. $7^{\text {th }}$ ed.; 427-39.

5. Nayar R, Solomon D. Second edition of The Bethesda System for reporting cervical cytologyAtlas, website, and Bethesda interobserver reproducibility project. Cyto Journal. 2004;1:4.

6. Manos MM, Kinney WK, Hurley LB. Identifying women with cervical neoplasia: Using Human Papilloma virus DNA testing for equivocal papanicolaou results JAMA. 1999;281:1605-10. 
7. Engineer AD, Misra JS. The role of routine outpatient cytological screening for early detection of carcinoma of cervix in India. Diagn Cytopathol. 1987;3(1);30-4.

8. Sherwani RK, Khan T, Akhtar K, Zeba A, Siddiqui FA, Rahman K, et al. Conventional Pap smear and liquid based cytology for cervical cancer screeningA comparative study. Journal of Cytology. 2007;24(4):167-72.

9. Luthra UK, Prabhakar AK, Seth P, Agarwal SS, Murthy NS, Bhatnagar P, et al. Natural history of precancerous and early cancerous lesions of uterine cervix. Acta Cytol. 1987;31(3):226-34.

10. Gehlot M, Hooja N, Lakhiwal MK. Correlation between colposcopy, cytology and histology in cervical lesions. J Obstet Gynecol India. 2001;51(5): 180-83.

11. Fonn S, Bloch B, Mabina M, Carpenter S, Cronje H, Maise C, et al. Prevalence of precancerous lesion and cervical cancer in South Africa-A Multicentric study. S Afr Med J. 2002;92(2):148-56.
12. Thulaseedharan VJ, Malila N, Hakama M, Esmy O $\mathrm{P}$, Cheriyan M, et al. Socio demographic and reproductive risk factors for cervical cancer-a large prospective cohort study from rural India. Asian Pacific J Cancer Prev. 2012;13(6):2991-5.

13. Misra JS, Srivastava S, Singh U, Srivastava AN. Risk factors and strategies for control of carcinoma cervix in India: hospital based cytological screening experience of 35 years. Indian journal of cancer. 2009;46(2);155-9.

14. Herrero R, Brinton L, Reeves W, Brenes M, Tenorio F, Britton R, et al. Sexual behaviour, veneral disease, hygiene practices, and invasive cervical cancer in a high risk population. Cancer. 1990;65:380-5.

15. Varghese C, Amma NS, Chitrathara K, Dhakad N, Rani P, Malathy L, et al. Risk factors for cervical dysplasia in Kerela, India. Bulletin of World Health Organization. 1999;77(3):281-3.

16. Sharpley M, Jordan J, Croft PR. A systemic review of post coital bleeding and risk of cervical cancer. $\mathrm{Br}$ J Gen Pract. 2006;56(527):453-60.

Cite this article as: Kaur T, Garg S, Mor S. Sociodemographic and reproductive risk factors in cervical cancer. Int $\mathbf{J}$ Reprod Contracept Obstet Gynecol 2016;5:1510-3. 